\title{
Influence of pectin-based and modified starch thickeners on the structural characteristics of low- calorie apple jam
}

\section{Iryna Sylka, Oleksandra Nemirich, Oksana Kyrpichenkova, Olena Matyiashchuk, Olena Pavliuchenko, Juliia Furmanova}

\author{
National University of Food Technologies, Kyiv, Ukraine
}

Keywords:

Keywords:

Jam

Stevia

Pectin,

low-calorie

Starch

\section{Article history:}

Received

15.08.2021

Received in revised

form 21.11.2021

Accepted

30.12 .2021

\section{Corresponding \\ author:}

Iryna Sylka

E-mail:

irinasilka@ukr.net

\section{DOI:}

$10.24263 / 2310-$

$1008-2021-9-2-8$

\section{Abstract}

Introduction. The aim of the study is to determine the effects of thickeners on the structural characteristics of low-calorie jam.

Materials and methods. The technology of apple puree jam with complete removal of refined sugar and with the addition of sweetener was studied. Research methods: calcium-pectate method for determination of pectin substances, refractometric method for determination of dry substances, method for determining the mass of the load to destroy the structure of the jam to determine its strength; profile method on a 10-point scale of correspondence of intensities of sensation of aromatic and taste properties.

Results and discussion. Removal of refined sugar from the recipe leads to deterioration of the structural characteristics of the jam. In order to determine the optimal quantitative ratios of ingredients, the dependence of physicochemical quality indicators of jam on the content of thickeners in it.

Reduction in the amount of sugar in the range of $100-333 \mathrm{~g} / 1000 \mathrm{~g}$ leads to a decrease in strength from $320 \mathrm{~g}$ to $160 \mathrm{~g}$. At the same time, a significant amount of dry matter is lost: from 65,2 to $45,2 \%$. Their number partially increases with increasing content of apple puree from $550 \mathrm{~g} / 1000$ $\mathrm{g}$ of jam (control sample) to $650 \mathrm{~g}$.

This explains the slight increase in titratable acids content from 1.0 to $1.5 \mathrm{mg} / 100 \mathrm{~g}$. The titratable acidity was main when choosing pectin as a food additive to improve the structural characteristics of the finished product. A sufficient amount of pectin can be considered $10 \mathrm{~g} / 1000 \mathrm{~g}$ of jam. The strength of the jam's structure at this amount is $300 \mathrm{~g}$. The addition of modified corn starch Regel $200 \mathrm{G}$ in the amount of $10 \mathrm{~g} / 1000$ $\mathrm{g}$ of finished product allows to stabilize the texture of the jam and maintains its strength..

The addition of stevia extract in the amount of $15 \mathrm{~g} / 1000 \mathrm{~g}$ is optimal. Further increase in the amount of stevia extract is not justified, because the taste remains intensely sweet and the difference is not particularly noticeable. The taste profile of the studied samples shows the preservation of sweet taste and a slight increase in the fullness of bitter taste.

Conclusion. Adding pectin and starch as thickeners to jam, which contains dry stevia extract and does not contain refined sugar allows to get low-calorie jam and preserve the sensory properties of the product. 


\section{Introduction}

The healthy food has led to interest in low-calorie food products (Manippa et al., 2021). There is a modern trend in restaurant business for development of food products sugar-free. Fruit gel is an intermediate moisture food containing fruit pulp, sugar, pectin, and acid. For a this product like jam, it is important to understand the relationships between the sensory perception of food gel and textural or rheological properties.

A new product like a low calorie fruit gel in which the sugar content is low has to be manufactured by controlling the sensory and textural perception of the product. The chapter describes the rheological behavior of fruit gels as influenced by alternative sweeteners by partial or full replacement of sucrose (Basy et al. 2021).

Confectionery is not an essential product, but it is in high demand. Among these products are jams, which together with other canned fruits and berries are a source of pectin and only organic ingredients, vitamins and minerals (Oliver, 2015; Wim et al., 2002). This biologically active substance has medicinal properties, has antibacterial properties (Wikiera et al. 2014). To make fruits available for consumption during off-season, the fruits are processed into shelf-stable products like jam (Shinwari et al., 2018). That is why this work proposes developed technology low-calorie jam.

Many works are devoted to the study of technologies and components in the production of jams and other fruit and berry products (Rafeek et al., 2015). One of the main characteristics of the jam is a jelly-like consistency. It is due to the interaction of sugar with pectin in the presence of a significant amount of organic acids (Figuerola et al., 2007).

According to the formula (Cervera-Chiner et al., 2021), the sugar-free jam is prepared from water, strawberries, pectin, maltodextrin, citric acid, sodium citrate and sucralose. The sugar-free jam has the advantages of reasonable formula, advanced process, healthy and nutritional product and the like.

Stevia is of great scientific and practical interest in the production of low-calorie foods and which, in addition to the formation of sweet taste, gives a functional focus to products using it (Muñoz-Almagro et al., 2021). Stevia leaf extract is zero-calorie. It is being used globally to reduce energy and added sugar content in foods (Ashwell et al., 2015).

However, the substitution of sucrose by stevia, as sweetening agent, could be a challenge for industry, since in addition to the sweet taste, other sensory features could modify the final product (Reale et al., 2020). Stevia gives a functional focus to products using it.

The sweet secret of stevia is a complex molecule called stevioside, which is a glycoside. It is this complex molecule and a number of other related substances that are responsible for the extraordinary sweetness of stevia (300 times sweeter than sucrose). Stevia extract is not fermented by microorganisms and does not stain jams. Overall, stevia shows promise as a new tool to help achieve weight management goals.

The importance of good practice in the use of stevia in foods has been described both as a potential health product and a sweetener (Wang et al., 2021). Based on recent reports, this work is considering adding stevia extract to the jam.

The aim of the study is to determine the effect of thickeners on the structural characteristics of low-calorie jam, to stabilize the texture of the jam, maintain the strength characteristic of the classic jam-like consistency 


\section{Materials and methods}

\section{Materials}

The study used model samples jam with sugary and sugary-free; puree from apple. Highly esterified apple's pectin brand WEJ-5 manufactured by Rektowin. Its physicochemical characteristics: gel strength $100 \pm 5^{\circ}$ SAG, degree of esterification 50 $55 \%$, $\mathrm{pH}$ of $1 \%$ solution $3,4 \pm 0,5$.

\section{Preparation of research samples}

Preparation of apple puree: sorted apple fruits are washed in cold water, crushed and cooked in a special dish until completely softened (the duration of the technological stage is not more than 15 minutes); grind through a special wiping sieve with a hole diameter of not more than $1,5 \mathrm{~mm}$.

Preparation of jam: apple puree is boiled, stirring constantly; add the required amount of sugar / sweetener, pectin concentrate solution and starch (duration of the technological stage $10-15$ minutes).

Packing: puree in a hot state at a temperature of $95-97^{\circ} \mathrm{C}$ is packed in a glass container; glass jars with jam are covered with lids and subjected to sterilization (duration of sterilization of jam in glass jars with a capacity of 0,5 liters -15 minutes, 1,0 liters -25 minutes); then the jars are sealed, turned upside down and cooled (Bekele et al., 2020).

\section{Experimental plan}

The study of the effect of a new food supplement with other ingredients requires further step-by-step research. The jam's recipe was supplemented with sweetener and gradually. Table 1 shows various ingredients for making jam.

\section{Ingredient composition of model samples}

Table 1

\begin{tabular}{|c|c|c|c|c|c|c|c|c|}
\hline \multirow[b]{2}{*}{ № } & \multirow[b]{2}{*}{ Ingredient } & \multicolumn{7}{|c|}{ Mass, $\mathrm{g}$} \\
\hline & & 氙 & 氞 & 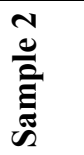 & m & 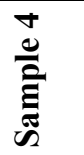 & 辱 & 吕 \\
\hline 1 & Puree from apple & 550 & 600 & 610 & 620 & 630 & 650 & 650 \\
\hline 2 & Water & 110 & 285 & 366 & 350 & 325 & 305 & 305 \\
\hline 3 & Sugar & 333 & 100 & - & - & - & - & - \\
\hline 4 & Stevia extract & - & 5 & 10 & 15 & 20 & 25 & 30 \\
\hline 5 & Apple's pectin & 7 & 5 & 7 & 10 & 15 & 20 & 30 \\
\hline 6 & Modified starch & - & 5 & 7 & 10 & 15 & 15 & 15 \\
\hline
\end{tabular}




\section{- Food Technology}

\section{Description of methods}

\section{Methods for determining dry soluble substances}

Refractometric method is to determine the mass fraction of dry matter in the product by the refractive index of its solution (Chen, 2019). For this purpose two drops of sample of model samples put on a prism of a refractometer. The sample was left in the refractometer to equilibrate thermally for two minutes and then the reading was performed. Temperature corrections are used to bring the refractometer reading to $20^{\circ} \mathrm{C}$. The repeatability determination was evaluated performing 10 subsequent measures under repeatability conditions on the same samples (Giulio et al., 2008).

\section{Method for quantitative determination of pectin substances}

This method including the conversion of pectin into a solution, demethoxylation with alkali and treatment of the resulting pectic acid solution with a calcium compound. The treatment of the pectic acid solution is carried out its hydroxide by titration with calcium in the presence of 0.002 wt. including copper acetate and including sodium chloride per $1 \mathrm{wt}$. including pectin (Yu. et al., 2021).

Mass fraction of pectin in the sample X,\% was determined:

$$
X=\frac{10^{4} m_{2} v \cdot 0.9235}{m v_{1}(100-W)}
$$

where $\mathrm{m}_{2}$ - the mass of the precipitate is calcium pectate, $\mathrm{g} ; \mathrm{v}-$ total amount of extract, $\mathrm{cm}^{3}$; 0,9235 - conversion factor of calcium pectate; $\mathrm{m}$ - the mass of the product, $\mathrm{g} ; \mathrm{v}_{1}$ - the amount of extract taken to determine pectin, $\mathrm{cm}^{3} ; \mathrm{W}$ - mass fraction of water in the product, $\%$.

\section{Method for determining the strength of the jam}

The method is based on determining the mass of the load required to destroy the structure of the gem. The essence of the method: a sample of $30 \mathrm{ml}$ in a cylindrical container is subjected to destruction by loading at a rate of $10-15 \mathrm{~g} / \mathrm{min}$. The mass of the load, which was critical, was recorded.

\section{Expert method of sensory evaluation}

The expert method of values quality indexes determination is based on committing the thought of the highly skilled and experienced specialists-experts (The expert of - it a specialist on the certain type of object which owns the increased sensitiveness to properties of this object) (Kuzmin et al., 2020a). The intensity was evaluated on a 10-point scale.

\section{Results and discussions}

Acording the objectives of the study, it is proposed to make some samples. One of them contained sugar and complied with regulations. The remaining samples $2-6$ were prepared without sugar. Based on the results of modern scientists, it was decided to add dry extract of stevia leaves as an additional source of sweet taste (Roik et al., 2015). Modified starch and 
pectin were included in the recipe to ensure normalized physicochemical quality indicators (Dangi et al., 2021).

The creation of new low-calorie jam provides for the following:

- Justification for the use of stevia extract in the production of jam based on apple puree;

- Reduction of energy value of the product due to removal (reduction) of sugar;

- Replacement of refined sugar with stevia extract while maintaining consistency by adding pectin and modified starch;

- Determination of physico-chemical quality indicators of the developed product;

- Determination of sensory assessment of the quality of test specimens according to regulatory documentation.

When adding a new ingredient to the recipe, it is necessary to determine the optimal mass and method of application. The results obtained from the samples were compared to show the differences among them. Especially important determine at which technological stage the application of food additives will have the best results.

\section{Dry matter content}

The Figure 1 shows that the reduction in the amount of refined sugar (sample 1) and its extraction (samples 2-6) leads to a decrease in the amount of dry matter, which can lead to loss of structure of the jam. Increasing the amount of stevia extract from $5 \mathrm{~g}$ to $30 \mathrm{~g}$ per 100 $\mathrm{g}$ of product affects the dry matter content very little. This means that you need to conduct a sensory evaluation of the quality of the finished product.

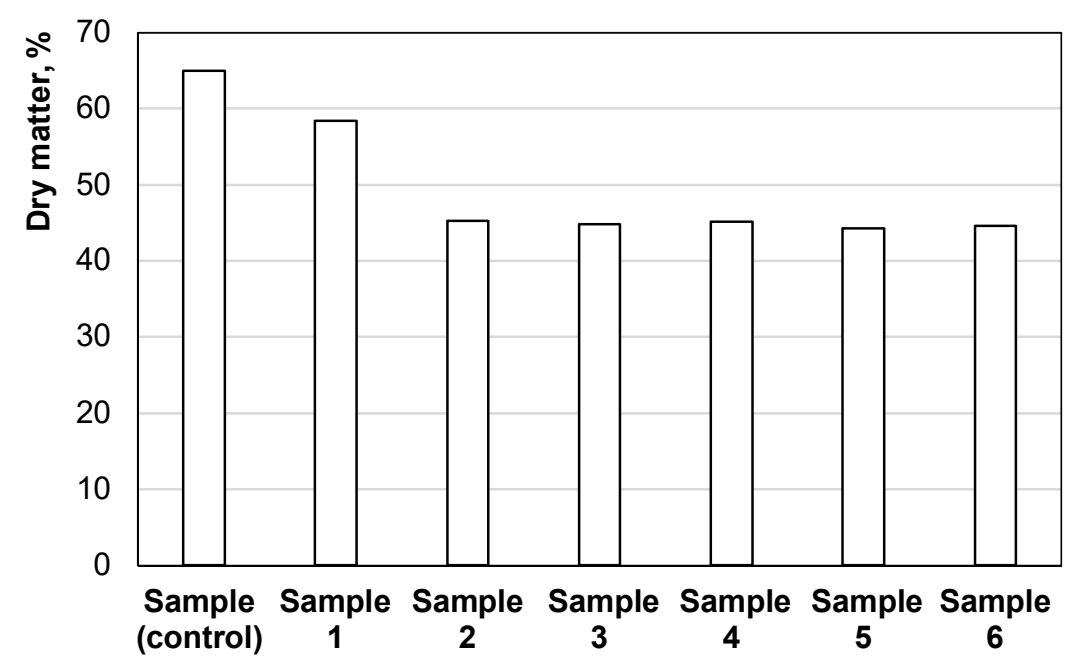

\section{Analysis of titrated acidity of samples}

The addition of various amounts of apple puree in the samples helps to increase the mass fraction of titrated acids due to organic acids that are part of fruit puree (Figure 2). That will allows extending the shelf life of jams and prevents microbiological spoilage (Shinwari, 2018). 


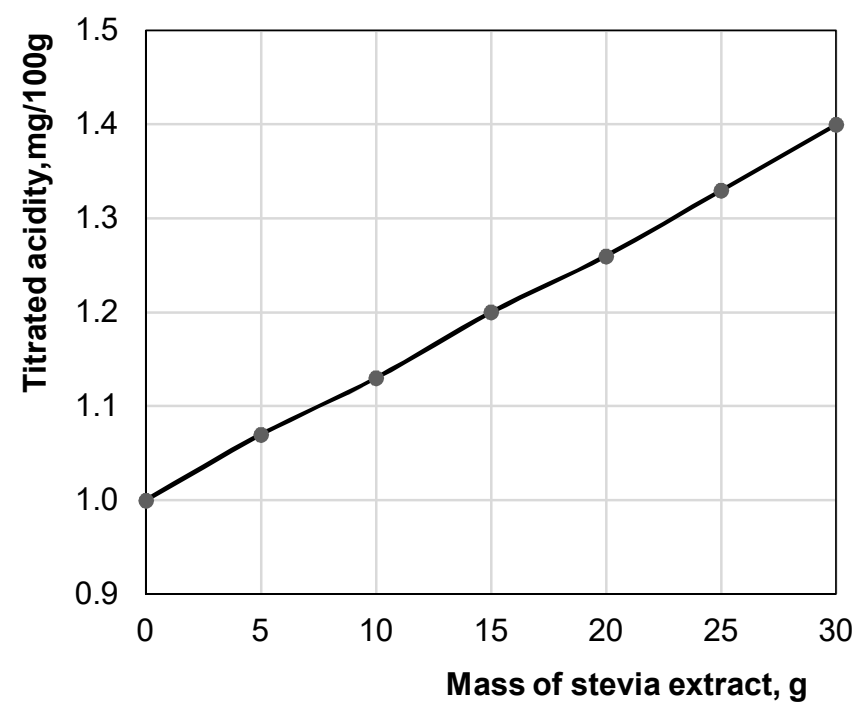

Figure 2. Dependence of mass fraction of titrated acids on stevia content

The titrated acids found in this study was in the range of $1.0-1.5 \mathrm{mg} / 100 \mathrm{~g}$, showing significant differences among the acidity of six samples. This is due to the increase in the amount of apple puree of 550-650 g per $1000 \mathrm{~g}$ (Table 1). In jams with a mild sour taste and high $\mathrm{pH}$, pectin should be used. Especially if the dry matter is $60-68 \%$. If you use very sour fruits and berries or use a lot of acid to taste, low $\mathrm{pH}$ requires medium or slow pectin. Quickrelease pectin is able to gel even when the dry matter content is $55 \%$, but sometimes it is used when the dry matter content is $55-60 \%$ (Bekele et al., 2020).

\section{Strength of samples}

Strength is the most important indicator for culinary dishes with a jam-like structure, which determines most of their organoleptic characteristics. Strength is studied at the end of the process of structure formation of the gel, which lasts depending on its prescription composition and the concentration of the main prescription components. According with data Krzysik et al., (2020) highly esterified apple pectin of the WEJ-5 brand manufactured by Rektowin was selected. The results of the study of strength are shown in Figure 3.

The figure shows that the strength of the studied samples of jam is in the range of 160 $330 \mathrm{~g}$. The highest value of strength reaches samples 4-6. This amount of the pectin (15-30 $\mathrm{g}$ ) is not acceptable enough for apple jam, which naturally contains a significant amount of pectin. It does not meet the daily needs of pectin consumption (Muñoz-Almagro et al., 2020). We consider optimal sample 3 , the strength of which is $300 \mathrm{~g}$, pectin $-10 \mathrm{~g} / 1000 \mathrm{~g}$. This value lies in the rational range of strength of control samples with the addition of sugar, which is $320 \mathrm{~g}$.

However, pectin is a rather expensive component and is strictly regulated in terms of content, so it is advisable to replace some of it with modified starch. Oxidized starches are of the greatest interest in the production of restaurant establishments. 


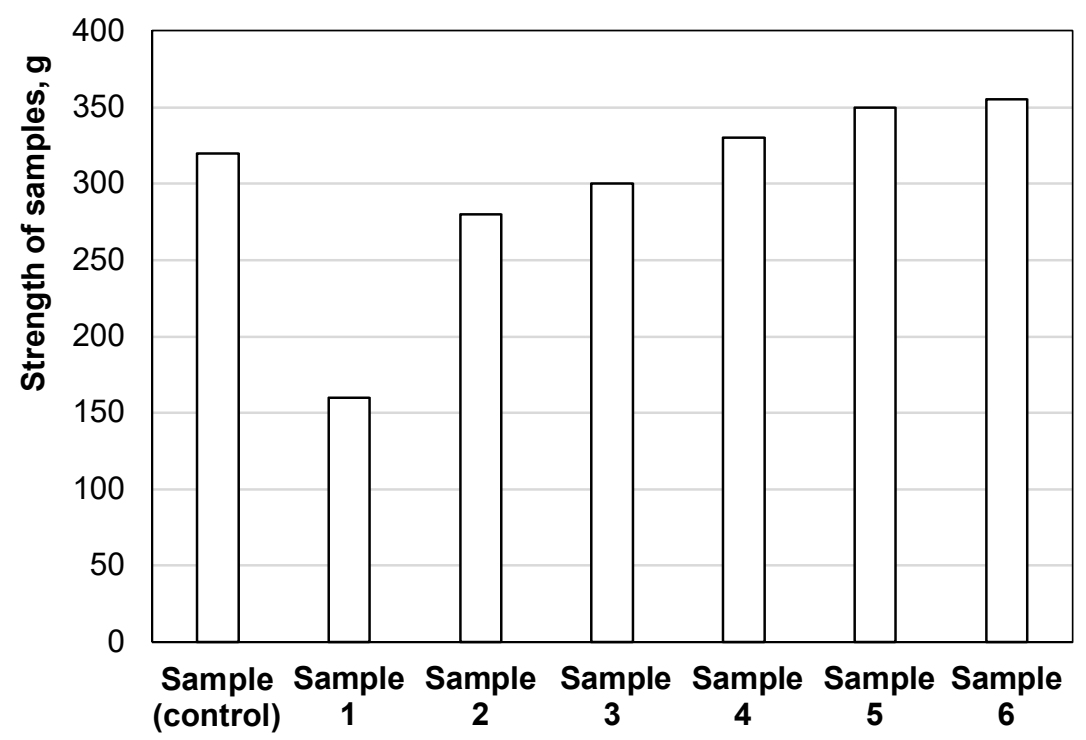

Figure 3. Dependence of strength of samples

The next step is study of the degree of swelling of the modified starch (Figure 3).

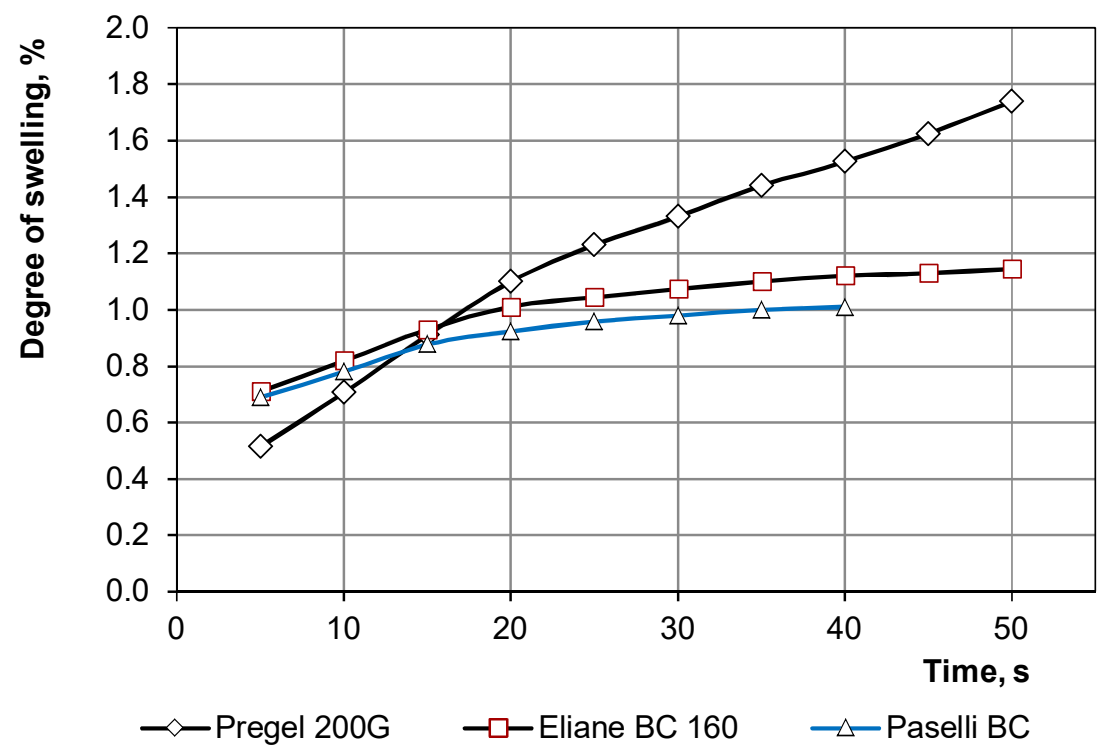

Figure 3. Changing the degree of swelling of the modified starch depending on the duration of swelling 
It was determined that the greatest degree of swelling has a modified corn starch Regel $200 \mathrm{G}-1,75 \%$. choosing.

Hydration function of modified starches (Table 2) is its main characteristic when

Table 2

\section{Degree of hydrophilicity of modified starches}

\begin{tabular}{|c|c|}
\hline Name of the hydrocolloid & Hydrophilicity, \% \\
\hline Potato elianebc 160 & 36,7 \\
\hline Potato pasellibc & 25,9 \\
\hline Corn Regel 200 G & 43,5 \\
\hline
\end{tabular}

Thus, based on the technical data of the manufacturer, it is found that the optimal is modified corn starch Regel $200 \mathrm{G}$ hydrophilicity of which is $43,5 \%$. Using the latter will help create heat-reversible gels and reduce the amount of sugar in the products.

Through theoretical calculations and experimental studies, it was possible to establish the optimal recipe of the jam, which includes stevia extract powder, apple pectin and modified starch. This is the sample 3 .

\section{Formation of the quality of the jam}

According to organoleptic indicators, jams must comply with sample control and some the indicators (Bekele et al., 2020). During the preparation of jam based on apple puree, a sensory evaluation of the obtained samples was performed. The essence was to decompose the taste into simple components (sweet, salty, bitter, spicy, sour, tart) intensity. Figure 4 shows the profile of samples 1, 2, 3, 4 and control.

The taste of stevia extract remains intensely sweet and the difference is not particularly noticeable. It was found that the closest to the control sample is the sample 2. This means that the optimal concentration of sweetener that can be introduced is $10 \mathrm{~g}$ per $1000 \mathrm{~g}$ of finished product. The subsequent increase in the amount of stevia extract leads only to the deterioration of flavoring properties.

The characteristics of the test samples are presented in Table 3.

Table 3

Characteristics of the model samples

\begin{tabular}{|l|l|l|}
\hline Characteristic & \multicolumn{1}{|c|}{ Sample control } & \multicolumn{1}{c|}{ Sample 2 } \\
\hline Appearance & $\begin{array}{l}\text { Inherent in jam, transparent } \\
\text { homogeneous mass }\end{array}$ & Light yellow homogeneous mass \\
\hline Color & $\begin{array}{l}\text { Inherent in apple jam, has a } \\
\text { light yellow hue }\end{array}$ & $\begin{array}{l}\text { Inherent in apple jam, has a yellow } \\
\text { tinge }\end{array}$ \\
\hline Taste & Gentle, sweet & Pleasant, tender, sweet with bitterness \\
\hline Scent & Inherent in apple jam & Inherent in apple jam \\
\hline Consistence & $\begin{array}{l}\text { Homogeneous puree, well } \\
\text { spread }\end{array}$ & $\begin{array}{l}\text { Homogeneous jelly-like mass, does not } \\
\text { spread on a horizontal surface }\end{array}$ \\
\hline
\end{tabular}




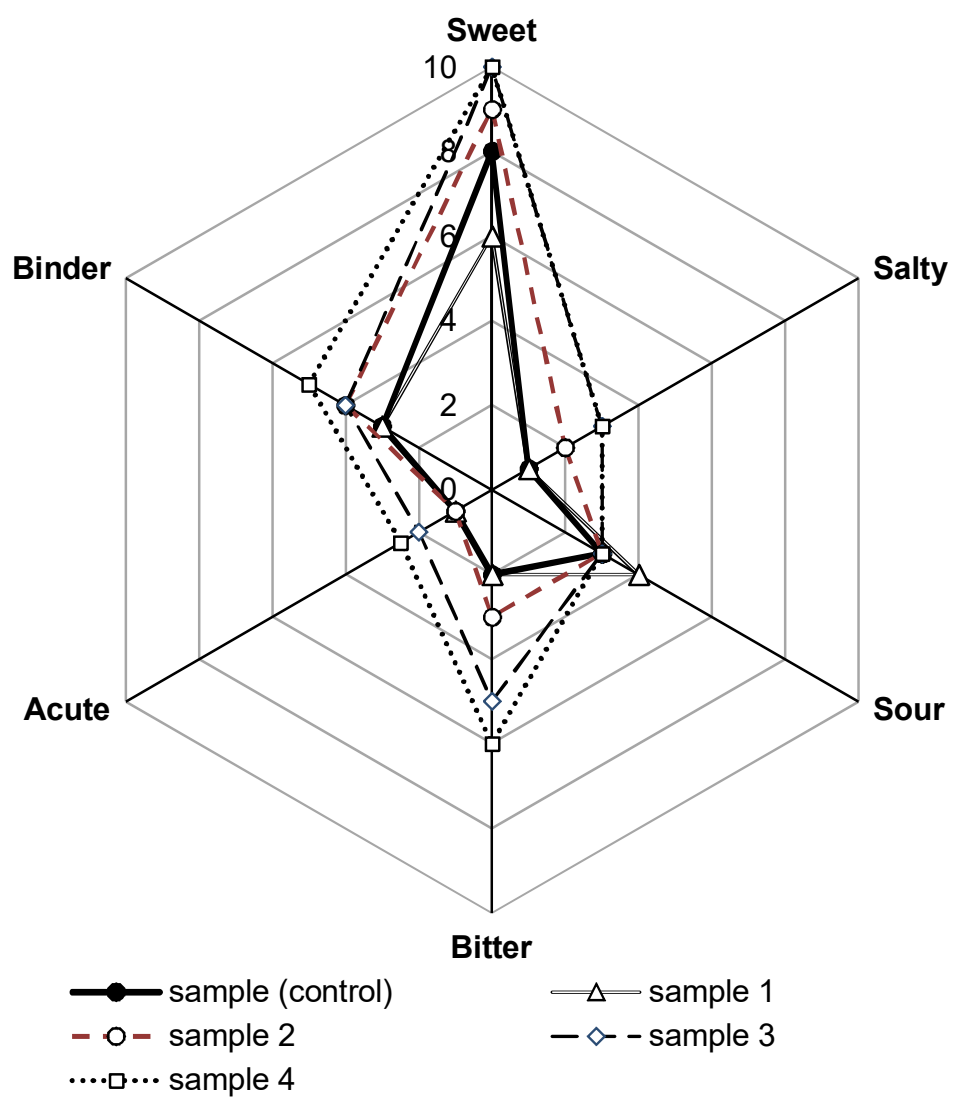

Figure 4. Sensory profilograms of samples

The main purpose of this work was to reduce the energy value and avoid refined sucrose. For this purpose, the search for the optimal recipe that will preserve the physical and chemical quality indicators.

Jam is mainly a source of carbohydrates (48-65\%) and its energy value is $183-$ $253 \mathrm{kcal} / 100 \mathrm{~g}$. From biologically active substances emit ascorbic acid. Its amount is depending on the type of raw material and cooking technology ranges from 1,5 to $53,3 \mathrm{mg}$ per $1000 \mathrm{~g}$ of product. Non-sterilized jams include more ascorbic acid than sterilized ones.

Despite all this, the main goal of this work was to reduce the energy value and avoid refined sucrose. For this purpose, the search for the optimal recipe that will preserve the physical and chemical quality indicators.

Analysis of the results of the calculation of energy characteristics shows that the main objective of the work has been achieved: the energy value of the low-calorie has been reduced to $123 \mathrm{kcal}$. It is slightly less than 2 times compared to apple jam (sample control). 
Nutritional value of low-calorie jam

\begin{tabular}{|l|c|c|c|}
\hline & Daily norm & Sample control & Low-calorie jam \\
\hline Energy value, kcal & 1684 & 250 & 123 \\
\hline Proteins, g & 76.0 & 0.4 & 1.6 \\
\hline Carbohydrates, g & 219.0 & 65.0 & 29.0 \\
\hline Dietary fiber, g & 20.0 & 2.3 & 4.3 \\
\hline Water, g & 22.7 & 32.9 & 63.9 \\
\hline
\end{tabular}

\begin{tabular}{|l|c|}
\hline & $\begin{array}{c}\text { Part of the norm } \\
\text { in jam in } \mathbf{1 0 0 g}, \mathbf{\%}\end{array}$ \\
\hline Energy value & 14.8 \\
\hline Proteins & 0.5 \\
\hline Carbohydrates & 29.7 \\
\hline Dietary fiber & 5 \\
\hline
\end{tabular}

\section{Conclusions}

1. According to the task of scientific work, it was studied influence and value of thickeners on the structural characteristics of low-calorie jam. Complete replacement of sugar with dry stevia extract in the recipe of low-calorie jam was made. It was found that the optimal concentration of sweetener is $10 \mathrm{~g} / 1000 \mathrm{~g}$ of finished product.

2. Theoretical calculations and experimental studies have established the optimal recipe for the low-calorie jam, which includes stevia extract powder, apple pectin and modified starch.

3. During creating a new jam, it is advisable to use modified corn starch Regel $200 \mathrm{G}$ in the amount of $10 \mathrm{~g}$ per $1000 \mathrm{~g}$ of finished product. It helps to create heat-reversible gels and reduce the amount of sugar in the products. We consider optimal sample 3 , the strength of which is $300 \mathrm{~g}$. This value lies in the rational range of strength of control samples with the addition of sugar, which is $320 \mathrm{~g}$.

4. Sensory evaluation of the model samples shows the preservation of sweet taste and a slight increase in the fullness of bitter taste. It was found that the closest to the control sample is the sample 3 . This means that the optimal concentration of sweetener that can be introduced is $10 \mathrm{~g}$ per $1000 \mathrm{~g}$ of finished product.

5. The energy value of the low-calories jam is $123 \mathrm{kcal}$. The share of energy value that satisfies $100 \mathrm{~g}$ of this jam $-7,3 \%$ of a daily requirement. Consumption of $674 \mathrm{~g}$ of lowcalorie jam will provide the daily norm of energy value.

\section{References}

Alija J., Talens C. (2012), New concept of desserts with no added sugar, International Journal of Gastronomy and Food Science, 1(2), pp. 116-122. 
Ashwell M. (2015), Stevia. Nature's Zero-Calorie Sustainable Sweetener, Nutr Today, 50(3), 129$134 \mathrm{pp}$.

Basu S., Shivhare U.S., Chakraborty P. (2017), Influence of Sugar Substitute in Rheology of Fruit Gel, Food Science, Technology and Nutrition, pp. 355-376

Belović M, Torbica A, Pajić-Lijaković I, Mastilović J. (2017), Development of low calorie jams with increased content of natural dietary fibre made from tomato pomace, Food Chem., 237, pp. 1226-1233.

Cervera-Chiner L., Barrera C., Betoret N., Seguí L. (2021), Impact of sugar replacement by noncentrifugal sugar on physicochemical, antioxidant and sensory properties of strawberry and kiwifruit functional jams, Heliyon, 7, pp. 2405-8440.

Cervera-Chiner L., Barrera C., Betoret N., Seguí L. (2021), Impact of sugar replacement by noncentrifugal sugar on physicochemical, antioxidant and sensory properties of strawberry and kiwifruit functional jams, Heliyon, 7, pp. 59-63.

Chen Y, LiuJ, YangZ, James S. Wilkinson, Zhou X. (2019), Optical biosensors based on refractometric sensing schemes, A review, Biosensors and Bioelectronics, $144 \mathrm{pp}$.

Dainelli D., Gontard N., Spyropoulos D., Zondervan-van den Beuken E., Tobback P. (2008), Active and intelligent food packaging: Legal aspects and safety concerns, Trends in Food Science \& Technology, 19(1), pp. 103-112.

Einhorn-Stoll U. (2017), Pectin-water interactions in foods - From powder to gel, Food Hydrocoll, 78, pp. 109-19.

Figuerola, F. (2007). Berry jams and jellies, Food Science and Technology, 13, pp. 367-386.

Frolova N., Ukrainets A., Sylka I., Nemirich A., Kuzmin O. (2019), Separation of terpenes from lemon essential oil by selective fractionation under a vacuum, Eastern-European Journal of Enterprise Technologies, 11 (98), pp. 32-36.

Garrido JI, Lozano JE, Genovese DB. (2015), Effect of formulation variables on rheology, texture, colour, and acceptability of apple jelly: Modelling and optimization. LWT, Food Science and Technology, 62, pp. 325-332.

Gloriana Rodríguez-Arauz (2022), A naturalistic observational study on food interactions and indicators of healthy and unhealthy eating in White-European and Latinx families, Appetite, 171, pp. 119-124.

Hrabovska O., Pastukh H., Lysyi O., Miroshnyk V., Shtangeeva N. (2018), The use of enzyme preparations for pectin extraction from potato pulp, Ukrainian Food Journal, 7(2), pp. 215-233.

Junyan Wang, Hongli Zhao, Yueming Wang, Hoching Lau, Wenhu Zhou, Chuanpin Chen, Songwen Tan (2020), A review of stevia as a potential healthcare product: Up-to-date functional characteristics, administrative standards and engineering techniques, Trends in Food Science \& Technology, 103, pp. 264-281.

Kalinowska M., Bielawska A., Lewandowski W. (2014), Apples: Content of phenolic compounds vs. variety, part of apple and cultivation model, extraction of phenolic compounds, biological properties, Plant Physiology and Biochemistry, 84, 169-188.

Kalinowska M., Bielawska A., Lewandowski W. (2014), Apples: Content of phenolic compounds vs. variety, part of apple and cultivation model, extraction of phenolic compounds, biological properties, Plant Physiology and Biochemistry, 84, 169-188.

Kuzmin O., Kucherenko V., Sylka I., Isaienko V., Furmanova Y., Pavliuchenko E., Hubenia V. (2020a), Antioxidant capacity of alcoholic beverages based on infusions from non-traditional spicy-aromatic vegetable raw materials, Ukrainian Food Journal, 9 (2), pp. $404-424$.

Kuzmin O., Sylka I., Frolova N., Popovych V., Kyrpichenkova O. (2020b), Ensuring the competitiveness of the restaurant business in Ukraine in the period Covid-19 pandemics, Pandemic Economic Crisis: Changes and New Challenges to Society: scientific monograph, Publishing House "St. Grigorii Bogoslov", Sofia.

M. Moldão-Martins, N. Moreira, I. Sousa, M.L. Beirão da Costa (1998), Effect of processing 
conditions on volatile composition of apple jellies and jams, Developments in Food Science, 40, pp. 369-374.

Manippa V., Ferracci S., Pietroni D., Brancucci A. (2021), Can the position on the screen of an image influence its judgment? The case of high- and low-calorie foods, Food Quality and Preference, 96, pp. 20-26.

Melkam Bekele, Neela Satheesh, Sadik J.A (2020), Screening of Ethiopian mango cultivars for suitability for preparing jam and determination of pectin, sugar, and acid effects on physico-chemical and sensory properties of mango jam, Scientific African, 7, pp. 115123.

Monika Krzysik, Halina Grajeta, Anna Prescha, Ryszard Weber (2011), Effect of cellulose, pectin and chromium(III) on lipid and carbohydrate metabolism in rats, Journal of Trace Elements in Medicine and Biology, 25, pp. 97-102.

Nerea Muñoz-Almagro, Antonia Montilla, Mar Villamiel (2021), Role of pectin in the current trends towards low-glycaemic food consumption, Food Research International, 140, pp. 86-94.

Nerea Muñoz-Almagro, Mar Villamiel, Peter J. Wilde, A. Patrick Gunning, Antonia Montilla (2021), Effect of sucrose substitution with stevia and saccharin on rheological properties of gels from sunflower pectins, Food Hydrocolloids, 120, pp. 106-110.

Nidhi Dangi, Baljeet S. Yadav, Ritika B. Yadav (2020), Pectin and its acid hydrolysate for the modification of hydration, pasting, thermal and rheological properties of barley starch, International Journal of Biological Macromolecules, 152, pp. 969-980.

Niemirich O., Pogozhich M., Petrusha O., Havrysh A., Vasheka O. (2017), Restoring and emulsifying properties of the dried meat semi-finished product, Ukrainian Food Journal, 6(2), pp. 302-314.

Oliver Jamie (2015), Everyday Super Food Hardcover, Penguim.

Reale A, Di Renzo T, Russo A, Niro S, Ottombrino A, Pellicano M. (2020), Production of lowcalorie apricot nectar sweetened with stevia: Impact on qualitative, sensory, and nutritional profiles. Food Sci Nutr., 8(4), pp. 1837-1847.

Shinwari K.J., Rao P.S. (2018), Stability of bioactive compounds in fruit jam and jelly during processing and storage: A review, Trends in Food Science \& Technology, 75, pp. 181193.

Sylka I., Stukalska N. (2020), A report on the 1-st International Scientific and Practical Conference: Recent Scientific Investigation: Technologys of confectionery products gluten-free in restaurants, Scientific Collection «InterConf», 6, pp. 977 - 981.

Tomás-Barberán F.A., García-Viguera C., Nieto J.L., Ferreres F., Tomás-Lorente F. (1993), Dihydrochalcones from apple juices and jams, Food Chemistry, 46, pp. 33-36.

Wanmeng Mu, Yanyan Zhang, Lutz Fischer, Bo Jiang (2020), A report on the 2nd ChineseGerman symposium: Functional and healthy food ingredients: Emerging insights and technologies, Trends in Food Science \& Technology, 99, pp. 472-473.

Wikiera A., Irla M., Mika M. (2014)., Health-promoting properties of pectin, Postepy higieny $i$ medycyny doswiadczalnej, 68, pp. 590-596.

Zeeb B., Roth M., Endre H.U. (2020), Chapter 10: Commercial pectins, Handbook of Hydrocolloids (Third Edition), pp. 295-315. 